\title{
Opioid Prescribing on an Internal Medicine Teaching Unit
}

Samuel Quan, Cheyenne Lawton, Allison Budd, MD, FRCPC

Department of Medicine, University of Saskatchewan, Saskatoon, Canada

Author for correspondence: Allison Budd:acb782@mail.usask.ca

Received: 13 July 2020; Accepted after revision: 24 November 2020; Published: 21 June 2021

DOI: https://doi.org/10.22374/cjgim.v16i2.443

\section{ABSTRACT}

\section{Objective}

To investigate the rationale and timing of opioid prescriptions for Internal Medicine inpatients in an academic center in Saskatoon, Canada.

\section{Methods}

We performed a cross-sectional study of Internal Medicine inpatients that were prescribed opioids in Saskatoon. We examined documentation of clinical rationale and timing of opioid initiation or first escalation.

\section{Results}

Of 57 patients, 34 (60\%) were opioid naive prior to admission and 48 (84\%) had opioid doses either initiated or escalated. Of these 48 patients, 27 (56\%) occurred during on-call hours. Rationale for escalation was documented in 31 cases $(65 \%)$, with reasons including terminal care (17\%), musculoskeletal pain (15\%), and skin and soft tissue infections (13\%).

\section{Conclusion}

Rationale for opioid use was frequently not documented. Initial decision to change opioid dose occurred equally between daytime and on-call hours.

\section{RÉSUMÉ}

\section{Objectif}

Étudier la justification et le moment choisi pour prescrire des opioïdes chez les patients hospitalisés en médecine interne dans un centre universitaire de Saskatoon (Canada).

\section{Méthodologie}

Nous avons mené une étude de prévalence sur des patients hospitalisés en médecine interne chez qui on a prescrit des opioïdes à Saskatoon. Nous avons examiné la documentation concernant la justification clinique et le moment choisi pour entreprendre le traitement par les opiö̈des ou effectuer la première augmentation de dose. 


\section{Résultats}

Des 57 patients, 34 (60\%) n’avaient jamais pris d'opioïdes avant leur hospitalisation et $48(84 \%)$ ont reçu leur première dose d'opioïdes ou une augmentation de dose. De ces 48 patients, 27 (56\%) ont reçu leur dose durant les heures de garde. La justification de l'augmentation de dose est documentée dans 31 cas (65\%), les raisons étant les soins de fin de vie (17\%), la douleur musculosquelettique (15\%) et les infections de la peau et des tissus mous (13\%).

\section{Conclusion}

Souvent, la justification de l'utilisation des opioïdes nest pas documentée. Le moment où la décision initiale de modifier la dose d’opioïde est prise est réparti de façon égale entre le jour et durant les heures de garde.

\section{Introduction}

Canada is in the midst of an opiate crisis. Hospitalizations due to opiate poisoning have been increasing in Canada. ${ }^{1,2}$ This crisis is in part driven by legal prescriptions, ${ }^{2}$ making stewardship of opioid prescribing more important than ever. As part of the effort to mitigate opioid-related morbidity and mortality, Canadian guidelines ${ }^{3,4}$ recommend cautious opioid prescribing and optimizing adjuvant pain control prior to starting opioids.

Multiple studies address opioid prescribing on surgical units, but few studies have evaluated opioid use among medical inpatients. ${ }^{5}$ Internal medicine (IM) units care for patients with a variety of presenting illnesses, many of which involve acute or chronic pain. Nonopioid analgesics are recommended by multiple guidelines prior to and along with opioids, ${ }^{3,4}$ but this practice is not well studied within the IM inpatient population. Our study investigated the rationale, timing, and use of adjunct therapies associated with opioid prescriptions on IM inpatients in an academic hospital in Saskatoon, Canada.

\section{Methods}

A retrospective chart review with a cross-sectional design was conducted investigating events surrounding the initiation or escalation of opioid-prescribing practices for IM inpatients.

\section{Population and Data Sources}

We identified inpatients admitted to an IM clinical teaching unit (CTU) at Royal University Hospital (RUH) between July 1, 2017 and June 30, 2018 who were given at least one in-hospital opioid prescription. RUH is a tertiary academic center in Saskatoon, Canada. Patients who underwent neuraxial or general anesthesia within 30 days of admission or were prescribed methadone or suboxone in the community were excluded. Opioids given for major procedures (e.g., cardiac catheterization) were excluded.

Patients were identified using the RUH inpatient pharmacy database, BDM Pharmacy. BDM Pharmacy tracks all inpatient medication orders as well as the inpatient unit that patients are discharged from. A list of inpatients discharged from an IM CTUspecific ward with opioid prescriptions was generated by BDM Pharmacy, and 60 unique IM patients were chosen by simple random sample for chart review. If patients had multiple CTU admissions within the study period, the first one was selected.

\section{Chart review and Variables Collected}

Details of opioid initiation or first escalation including the opioid dose, route, frequency, service, who wrote the order, clinical rationale for opioid use, and whether opioids were ordered during daytime or on-call coverage hours were gathered from chart review. Regular hours were defined as daytime (07:30-16:59) or on-call hours (17:00-07:29). Medication reconciliation of home medications, including opioids, was routinely performed for all inpatients at the time of admission. Patients were considered opioid naive if they did not have any active opioid prescriptions at the time of admission. Opioid prescriptions given at the time of discharge were also recorded.

Opioid escalation was defined as either: (i) an increase in opioid dose or frequency, (ii) administration of intravenous (IV) opioid, (iii) new breakthrough opioid dose prescribed (different from a patient's home opioid regimen), or (iv) a change in opioid type with a greater maximum dosage when converted to morphine equivalents.

Patient details were gathered, including age, sex, date of admission and discharge, past history of any substance abuse, and past or current liver disease. Prescriptions of adjunct analgesics prior to opioid initiation or escalation, including acetaminophen, nonsteroidal anti-inflammatory medications (NSAIDs), pregabalin, or gabapentin, were recorded.

\section{Statistical Analysis}

Descriptive results were reported in medians with interquartile ranges (IQR) or percentages. Characteristics were compared 
between opioid-tolerant (with escalated doses) and opioid-naive patients using student's $t$-test or chi-square tests. A sensitivity analysis was performed excluding patients who died in-hospital. STATA version 13 was used.

\section{Ethics Approval}

Ethics approval was granted by the University of Saskatchewan Health Research Ethics Board (\#15-90).

\section{Results}

BDM pharmacy identified 704 IM patients admitted to CTU and were prescribed opioids in-hospital, and 60 (8.5\%) were randomly selected for review. We excluded three patients due to recent surgery. In this patient sample, the majority were elderly (median age 69) and opioid naive prior to admission (60\%; Table 1). Most patients, 48 of 57 (84\%), had opioid doses either initiated or escalated from baseline (Table 1).

Among IM inpatients, opioid escalations occurred similarly between on-call and day-time hours (56\% occurred on-call; 95\% CI: 42-70\%). Opioids were primarily prescribed by IM services (63\%; 95\% CI: 49-76\%). Among opioid escalations, hydromorphone was most commonly prescribed (78\%), followed by morphine (21\%); some patients had more than one opioid prescribed. After

Table 1. Characteristics of Internal Medicine Patients Who Received at Least One Opioid Prescription in Hospital

\begin{tabular}{|l|l|}
\hline \multicolumn{1}{|c|}{ Variable } & \multicolumn{1}{c|}{ n (\%) } \\
\hline Sample size & $\mathrm{n}=57$ \\
\hline Female & $29(51 \%)$ \\
\hline Age & Median: 69, IQR: 49-81 \\
\hline Opioid naïve & $34(60 \%)$ \\
\hline Opioid prescribed at home & \\
\hline Hydromorphone & $11(19 \%)$ \\
\hline Codeine & $4(7 \%)$ \\
\hline Fentanyl & $3(5 \%)$ \\
\hline Oxycodone & $3(5 \%)$ \\
\hline Tramadol & $2(4 \%)$ \\
\hline Morphine & $2(4 \%)$ \\
\hline Frequency of home prescription & \\
\hline Scheduled & $7(12 \%)$ \\
\hline As needed & $10(18 \%)$ \\
\hline Both & $4(7 \%)$ \\
\hline History of substance abuse & $13(23 \%)$ \\
\hline History of liver diseases & $9(16 \%)$ \\
\hline Death in-hospital & $14(25 \%)$ \\
\hline
\end{tabular}

aSome patients were prescribed more than one type of opioid. excluding palliative cases and in-hospital deaths, four of the 24 (17\%) patients who were opioid-naive prior to hospitalization were given a new opioid prescription at discharge.

Documented rationale behind why opioids were started or escalated was missing for 17 of 48 (35\%; 95\% CI: 22-49\%) cases (Figure 1). Among documented cases, rationale included: terminal care (17\%), musculoskeletal pain (15\%), and skin and soft tissue infections (13\%).

Opioid-naive patients had similar characteristics compared to opioid tolerant patients (Supplement 1), except that escalation was less likely for skin and soft tissue infections $(\mathrm{P}<0.05)$. A sensitivity analysis was conducted, and results remain similar after excluding in-hospital deaths (Supplement 2).

Although acetaminophen was prescribed in $71 \%$ of the cases, only $31 \%$ of the patients had received acetaminophen within $4 \mathrm{~h}$ prior to opioid escalation, and only $48 \%$ had received acetaminophen within the previous $24 \mathrm{~h}$ (Figure 2). Acetaminophen $\geq 2$ g was rarely given in the $24 \mathrm{~h}$ prior to prescription (8\%). Among the other adjunct agents, pregabalin/gabapentin (17\%) and oral NSAIDs (15\%) were infrequently prescribed (Figure 3).

\section{Discussion}

We conducted a cross-sectional study evaluating opioid-prescribing patterns among IM inpatients in Saskatoon, Canada. Indications for opioid initiation or escalation varied, with terminal care being the most common reason, although documentation was not recorded in a third of cases. Opioids were initiated or escalated relatively equally between the on-call and day-time primary teams.

Opioids are frequently prescribed by IM physicians, highlighting the importance of increasing the understanding of opioid-prescribing patterns in IM. In a study examining over 56 million inpatient and outpatient opioid prescriptions, IM provided the second highest number of opioid prescriptions. ${ }^{6}$ Another study of over 1 million inpatients at 286 hospitals showed that opioids were used in $51 \%$ of nonsurgical admissions. ${ }^{7}$

Documentation of clinical rationale for opioid prescriptions is important, as opioids can be prescribed for a variety of syndromes. Previously opioid-naive patients sent home with opioid prescriptions are at an increased risk of opioid dependency. ${ }^{8}$ Improved communication techniques, such as writing the clinical indication in the order or the discharge prescription, may also help facilitate transfers of care, opioid tapering, and eventual discontinuation. Future studies should investigate the influence of improved documentation on opioid de-escalation and discontinuation.

Management of acute pain can be challenging on an inpatient service. Severe pain may require urgent initiation of analgesic, and patient's preconceived notions of nonopioid analgesics may 


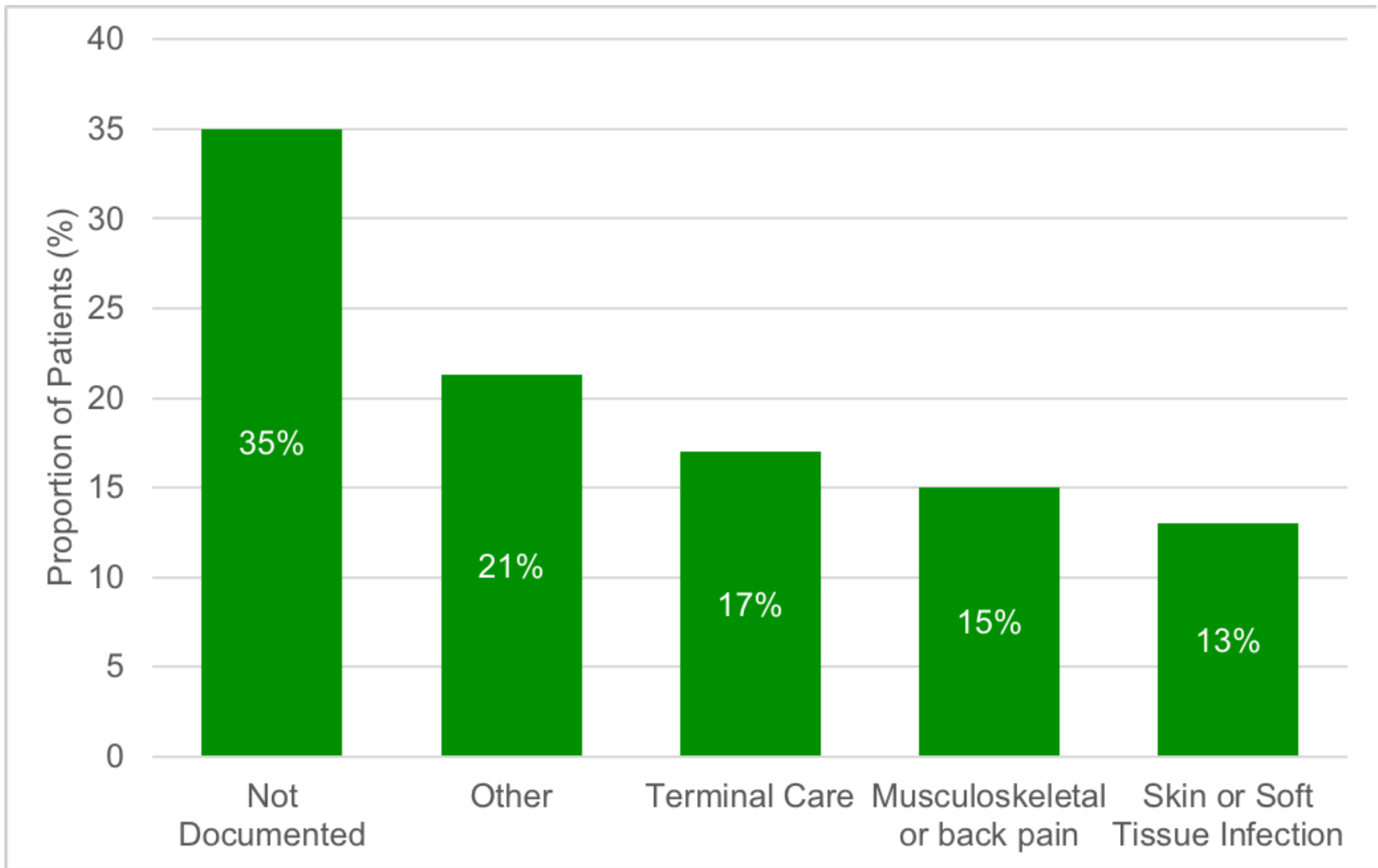

Figure 1. Indications documented for either initiation or escalation of opioids in-hospital.

influence choice of agent. Internists can face multiple competing demands, such as: imminently ill patients, a busy ward, or multiple consults for admission. Barriers to why nonopioid analgesics are underutilized prior to and in combination with opioid use on medical wards is a complex topic that warrants further study.

Canadian practice guidelines advise against initiating opioid therapy in chronic, noncancer pain unless nonopioid pain management strategies have been optimized. ${ }^{3,4}$ However, nonopioid analgesics were frequently underutilized in our study. Acetaminophen was included as an option on both ER and IM order sets at our institution. Acetaminophen was often ordered on an as-needed basis for patients in this sample, yet rarely administered. When given, it was in low doses; frequently less than half of the maximum daily dose and below limits considered safe even for use in patients with underlying liver dysfunction. A large cohort study of multiple hospitals in Pennsylvania ${ }^{5}$ found a minority, approximately $20 \%$, of nonintensive care inpatient opioid users received either acetaminophen or NSAIDs. The authors state that although some inpatients may have contraindications to certain analgesics (e.g., peptic ulcer disease for NSAIDs), the authors stated the prevalence of these conditions would not alone explain the discrepancy in nonopioid analgesic use. We recognize there are specific safety concerns related to NSAIDs, pregabalin, and gabapentin on IM units, where the majority of patients are elderly ${ }^{9}$ and/or have multiple comorbidities, but opioids are also associated with serious risks and adverse effects. ${ }^{3,4}$

A substantial proportion (17\%) of opioid escalations in this study was provided for terminal care; this may be partially explained by the increased breadth of IM practice at our center. At RUH, IM frequently provides terminal care, with palliative care available on a consulting basis. Intensive therapies, such as noninvasive ventilation, are provided in observation units on the ward under the care of IM, increasing the proportion of patients with severe illness in relation to centers where that level of care is provided in intensive care units.

Limitations of our study include its small sample size and focus on opioid prescribing at a single academic hospital. Future research conducted at other centers would be valuable to better understand opioid prescription practice patterns on IM wards. Contraindications to nonopioid analgesics, such as peptic ulcer disease or renal dysfunction for NSAIDs, were beyond the scope of this study. Finally, we did not investigate how inpatient 


\section{A $80 \%$}
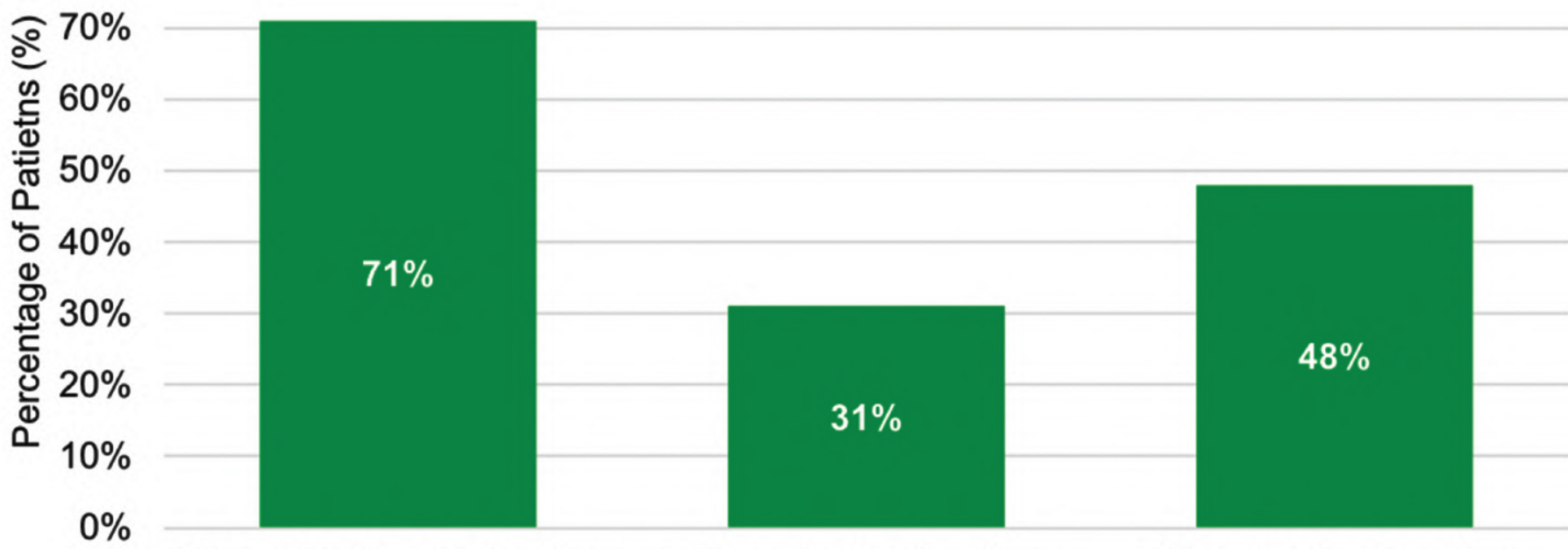

\section{Prescribed Acetaminophen}

B

$60 \%$

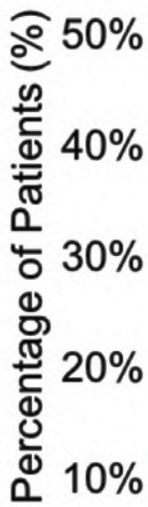

$0 \%$
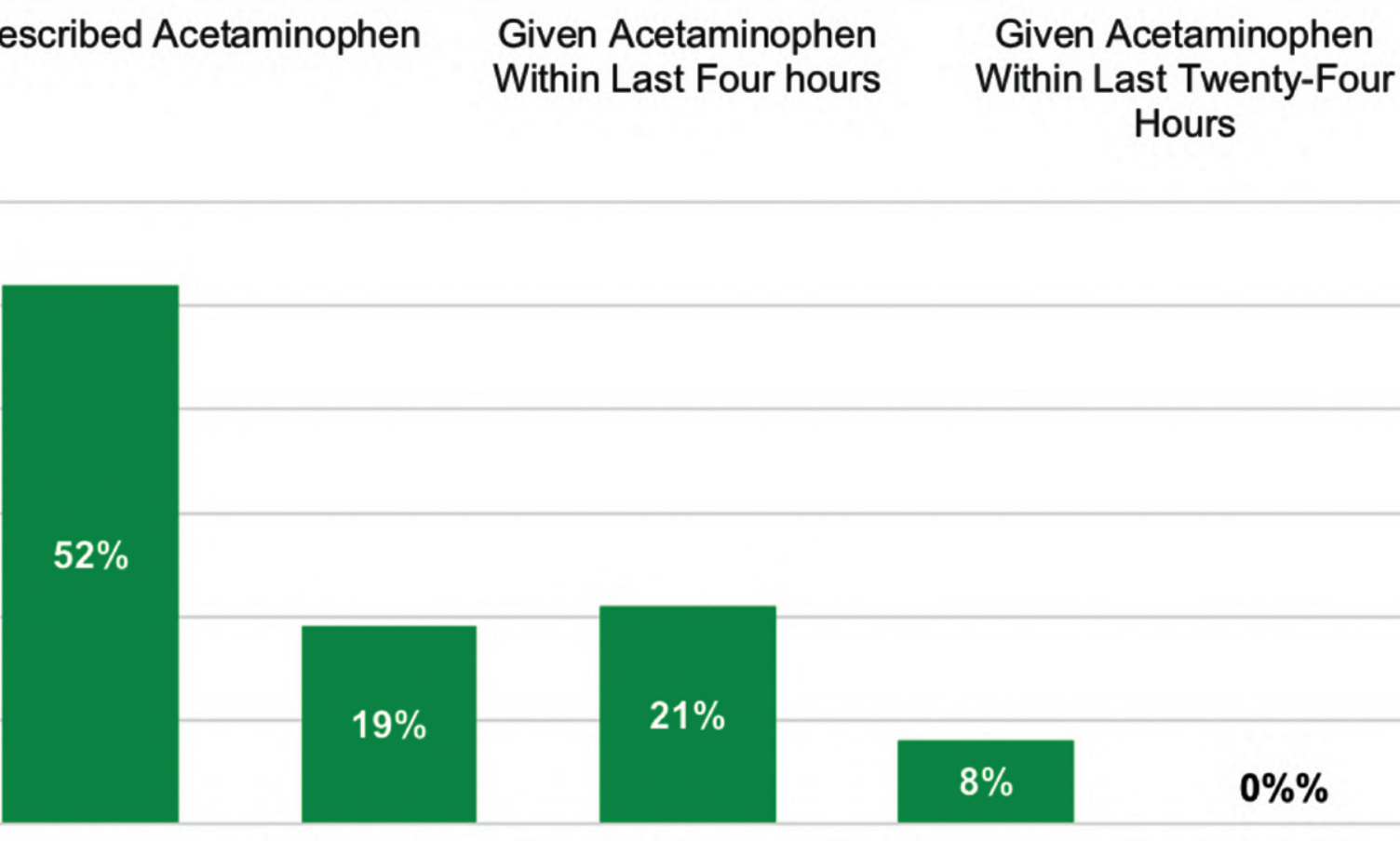

Hours

None

$325 \mathrm{mg}-1$ gram

1-2 grams

$8 \%$

$0 \% \%$

\section{Quantity of Acetaminophen Given}

Figure 2. Acetaminophen prescription orders and administration prior to initial decision to initiate or escalate opioids among internal medicine inpatients.

(A) Proportion of patients for whom acetaminophen is prescribed, and provided within 4 and $24 \mathrm{~h}$ prior to opioid initiation or escalation. (B) Total dose of acetaminophen provided within $24 \mathrm{~h}$ of initial opioid order.

prescriptions affect clinical outcomes, such as chronic opioid dependence or adverse effects.

\section{Sources of Funding and Support}

The University of Saskatchewan reimbursed CL for travel expenses in order for her to present the study as a poster presentation at the 2019 Canadian Society of Internal Medicine Conference. There were no other sources of funding.

\section{Acknowledgements}

We thank Leah Heilman for her contribution in providing data from the inpatient hospital pharmacy database, BDM Pharmacy. 


\section{Author Contributions}

$S Q, C L$, and $A B$ participated in generating the research idea and study design. SQ and CL gathered the data. SQ, CL, and AB participated in the data analysis and/or interpretation of results. $\mathrm{SQ}, \mathrm{CL}$, and $\mathrm{AB}$ all contributed to the writing and revisions in the manuscript. $A B$ provided guidance, supervision, and mentorship. All authors approved of the final version of the manuscript.

We can confirm that this work, neither in part or in whole, has not been published previously (with the exception as an abstract/poster presentation at the 2019 Canadian Society of Internal Medicine (CSIM) Conference and the 2019 University of Saskatchewan Resident Research Day presentations), nor is it currently being considered for publication elsewhere.

\section{Conflicts of Interest}

None.

\section{References}

1. Special Advisory Committee on the Epidemic of Opioid Overdoses. National report: Opioid-related Harms in Canada web-based report [Internet]. Ottawa: Public Health Agency of Canada; 2019. Available from: https:// health-infobase.canada.ca/substance-related-harms/opioids

2. Lisa B, Jessica H. Evidence synthesis - The opioid crisis in Canada: A national perspective. Health Promot Chron Dis Prevent Can Res Policy Pract. 2018;38(6):224-33. http://dx.doi.org/10.24095/hpcdp.38.6.02
3. Opioid Wisely. Choosing wisely Canada [Internnet]. n.d. [cited 2020 Jan 30] Available from https://choosingwiselycanada.org/campaign/opioid-wisely/

4. Busse JW, Craigie S, Juurlink DN, Buckley DN, Wang L, Couban RJ, et al. Guideline for opioid therapy and chronic noncancer pain. Can Med Assoc J. 2017;189(18):E659-66. http://dx.doi.org/10.1503/cmaj.170363

5. Donohue JM, Kennedy JN, Seymour CW, Girard TD, Lo-Ciganic W-H, Kim $\mathrm{CH}$, et al. Patterns of opioid administration among opioid-naive inpatients and associations with postdischarge opioid use: A cohort study. Ann Intern Med. 2019;171(2):81-90. http://dx.doi.org/10.7326/M18-2864

6. Weiner SG, Baker O, Rodgers AF, Garner C, Nelson LS, Kreiner PW, et al. Opioid prescriptions by specialty in Ohio, 2010-2014. Pain Med. 2018;19(5):978-89. http://dx.doi.org/10.1093/pm/pnx027

7. Herzig SJ, Rothberg MB, Cheung M, Ngo LH, Marcantonio ER. Opioid utilization and opioid-related adverse events in nonsurgical patients in US hospitals. J Hosp Med. 2014;9(2):73-81. http://dx.doi.org/10.1002/jhm.2102

8. Calcaterra SL, Yamashita TE, Min SJ, Keniston A, Frank JW, Binswanger IA. Opioid prescribing at hospital discharge contributes to chronic opioid use. J Gen Intern Med. 2016;31(5):478-85. http://dx.doi.org/10.1007/ s11606-015-3539-4

9. Johnson AG, Day RO. The problems and pitfalls of NSAID therapy in the elderly (Part I). Drugs Aging. 1991;1(2):130-43. http://dx.doi. org/10.2165/00002512-199101020-00005

Supplement 1: Descriptive statistics stratified by opioid tolerant versus opioid naïve cases.

Supplement 2: Descriptive statistics of patients on internal medicine teaching units for whom opioids were either initiated or escalated, excluding patients who died in-hospital.

Table S1-1. Descriptions of patients and initial opioid prescriptions as stratified newly initiated opioid prescriptions versus patients who had opioids escalated from their home dose. P-values were calculated with student's t-test or $\chi$-square tests where appropriate

\begin{tabular}{|c|c|c|c|}
\hline Variable & $\begin{array}{c}\text { Opioid-tolerant } \\
\text { n (\%) }\end{array}$ & $\begin{array}{c}\text { Opioid-naïve } \\
\text { n (\%) }\end{array}$ & P-value \\
\hline Sample size & $\mathrm{n}=14$ & $\mathrm{n}=34$ & $\mathrm{~N} / \mathrm{A}$ \\
\hline \multicolumn{4}{|l|}{ Characteristics } \\
\hline Female & $9(64 \%)$ & $16(47 \%)$ & $P=0.278$ \\
\hline Age (years) & $\begin{array}{l}\text { Median } 61.5 \\
\text { IQR: } 41-82\end{array}$ & $\begin{array}{l}\text { Median } 73.5 \\
\text { IQR: } 49-82\end{array}$ & $P=0.315$ \\
\hline History of substance abuse & $3(21 \%)$ & $8(24 \%)$ & $P=0.875$ \\
\hline History of liver disease & $1(7 \%)$ & $7(21 \%)$ & $P=0.256$ \\
\hline Death in-hospital & $3(21 \%)$ & $10(29 \%)$ & $P=0.572$ \\
\hline \multicolumn{4}{|l|}{ Time of prescription } \\
\hline Day-time hours (07:30-17:00) & $4(29 \%)$ & $15(44 \%)$ & \multirow{3}{*}{$P=0.246$} \\
\hline On-call hours (17:01-07:29) & $10(71 \%)$ & $17(50 \%)$ & \\
\hline Not documented ${ }^{\mathrm{a}}$ & $0(0 \%)$ & $2(6 \%)$ & \\
\hline Time from admission to initial opioid prescription & $\begin{array}{l}\text { Median } 20 \mathrm{~h} \\
\text { IQR: } 3-44\end{array}$ & $\begin{array}{l}\text { Median } 38 \mathrm{~h} \\
\text { IQR: 7-102 }\end{array}$ & $P=0.413$ \\
\hline \multicolumn{4}{|l|}{ Service that wrote the prescription } \\
\hline Internal medicine & $6(43 \%)$ & $24(71 \%)$ & \multirow{3}{*}{$P=0.241$} \\
\hline Emergency medicine & $5(36 \%)$ & $7(21 \%)$ & \\
\hline Other & $3(21 \%)$ & $3(9 \%)$ & \\
\hline
\end{tabular}




\begin{tabular}{|c|c|c|c|}
\hline Variable & $\begin{array}{c}\text { Opioid-tolerant } \\
n(\%)\end{array}$ & $\begin{array}{c}\text { Opioid-naïve } \\
\text { n (\%) }\end{array}$ & P-value \\
\hline \multicolumn{4}{|l|}{ Opioid prescribed in hospital ${ }^{b}$} \\
\hline Hydromorphone & $13(93 \%)$ & $24(71 \%)$ & $P=0.095$ \\
\hline Morphine & $2(14 \%)$ & $8(24 \%)$ & $P=0.474$ \\
\hline Fentanyl & $0(0 \%)$ & $2(6 \%)$ & $N / A^{c}$ \\
\hline Codeine & $1(7 \%)$ & $0(0 \%)$ & $N / A^{c}$ \\
\hline Bella-donna suppository & $0(0 \%)$ & $1(3 \%)$ & $N / A^{c}$ \\
\hline \multicolumn{4}{|l|}{ Frequency of in-hospital prescription } \\
\hline Scheduled & $2(14 \%)$ & $1(3 \%)$ & \multirow{3}{*}{$P=0.255$} \\
\hline As needed & $11(79 \%)$ & $32(94 \%)$ & \\
\hline Both & $1(7 \%)$ & $1(3 \%)$ & \\
\hline \multicolumn{4}{|l|}{ Indication for opioid prescription or escalation } \\
\hline Not documented & $4(29 \%)$ & $13(38 \%)$ & $P=0.525$ \\
\hline Terminal care & $1(7 \%)$ & $7(21 \%)$ & $P=0.256$ \\
\hline Musculoskeletal & $3(21 \%)$ & $4(12 \%)$ & $P=0.389$ \\
\hline Skin and soft tissue infection & $4(29 \%)$ & $2(6 \%)$ & $P=0.031$ \\
\hline Other & $2(14 \%)$ & $8(24 \%)$ & $P=0.474$ \\
\hline
\end{tabular}

${ }^{a}$ Cases without documented tie of initial prescription were excluded in the comparison.

bome patients were prescribed more than one type of opioid.

'Statistical comparisons were not performed if zero cases were found in either group.

Table S2-1. Characteristics of Internal Medicine Patients Who Received at Least One Opioid Prescription in Hospital and Excluding Patients Who Died In-Hospital

\begin{tabular}{|c|c|}
\hline Variable & $n(\%)$ \\
\hline Sample size & $\mathrm{n}=43$ \\
\hline Female & $21(49 \%)$ \\
\hline Age & Median: 61 years, IQR: 44-77 \\
\hline Opioid naïve & $24(56 \%)$ \\
\hline \multicolumn{2}{|l|}{ Opioid prescribed at home ${ }^{a}$} \\
\hline Hydromorphone & $10(23 \%)$ \\
\hline Codeine & $3(7 \%)$ \\
\hline Fentanyl & $3(7 \%)$ \\
\hline Oxycodone & $2(5 \%)$ \\
\hline Tramadol & $2(5 \%)$ \\
\hline Morphine & $1(2 \%)$ \\
\hline \multicolumn{2}{|c|}{ Frequency of home prescription } \\
\hline Scheduled & $6(14 \%)$ \\
\hline As needed & $7(16 \%)$ \\
\hline Both & $3(9 \%)$ \\
\hline History of substance abuse & $11(26 \%)$ \\
\hline History of liver disease & $7(16 \%)$ \\
\hline
\end{tabular}

aSome patients were prescribed more than one type of opioid. 
Table S2-2. Descriptions of the Timing and Opioid Prescriptions Written for Patients for Whom Opioids Were Newly Initiated or Had Been Escalated from Their Home Dose, Excluding Patients Who Had Died in-Hospital

\begin{tabular}{|c|c|}
\hline Variable & n $(\%)$ \\
\hline Sample size & $\mathrm{n}=35$ \\
\hline \multicolumn{2}{|l|}{ Time of prescription } \\
\hline Day-time hours (07:30-17:00) & $13(37 \%)$ \\
\hline On-call hours (17:01-07:29) & $21(60 \%)$ \\
\hline Not documented & $1(3 \%)$ \\
\hline Time from admission to initial opioid prescription & Median 20 h; IQR: 3-81 \\
\hline \multicolumn{2}{|l|}{ Service that wrote the prescription } \\
\hline Internal medicine & $20(57 \%)$ \\
\hline Emergency medicine & $11(31 \%)$ \\
\hline Other & $4(11 \%)$ \\
\hline \multicolumn{2}{|l|}{ Opioid prescribed in hospital ${ }^{a}$} \\
\hline Hydromorphone & $26(74 \%)$ \\
\hline Morphine & $8(23 \%)$ \\
\hline Fentanyl & $1(3 \%)$ \\
\hline Codeine & $1(3 \%)$ \\
\hline Bella-donna suppository & $1(3 \%)$ \\
\hline \multicolumn{2}{|l|}{ Frequency of in-hospital prescription } \\
\hline Scheduled & $2(6 \%)$ \\
\hline As needed & $31(89 \%)$ \\
\hline Both & $2(6 \%)$ \\
\hline \multicolumn{2}{|l|}{ Indication for opioid prescription or escalation } \\
\hline Not documented & $13(37 \%)$ \\
\hline Musculoskeletal & $7(20 \%)$ \\
\hline Skin and soft tissue infection & $6(17 \%)$ \\
\hline Other & $9(26 \%)$ \\
\hline
\end{tabular}

asome patients were prescribed more than one type of opioid. 